\title{
Correction to: Factors associated with poor treatment outcome of tuberculosis in Debre Tabor, northwest Ethiopia
}

Addisu Melese ${ }^{1 *}$ (1) and Balew Zeleke ${ }^{2}$

\section{Correction to: BMC Res Notes (2018) 11:25} https://doi.org/10.1186/s13104-018-3129-8

Following publication of the original article [1], similarity with another article by the same authors was reported. The authors would like to clarify that the current study [1] is an update of previous work that used the same data set in the analysis [2]. In Melese and Zeleke [1], the authors found that factors associated with poor treatment outcome were not sufficiently addressed previously. As a result of the reanalysis the effective sample size has changed.
References

1. Melese A, Zeleke B. Factors associated with poor treatment outcome of tuberculosis in Debre Tabor, northwest Ethiopia. BMC Res Notes. 2018;11:25. https://doi.org/10.1186/s13104-018-3129-8.

2. Melese A, Zeleke B, Ewnete B. Treatment outcome and associated factors among tuberculosis patients in Debre Tabor, Northwestern Ethiopia: a retrospective study. Tuberc Res Treat. 2016;2016:8. https://doi. org/10.1155/2016/1354356

\section{Publisher's Note}

Springer Nature remains neutral with regard to jurisdictional claims in published maps and institutional affiliations.

\section{Author details}

1 Department of Medical Laboratory Science, College of Health Sciences, Debre Tabor University, P.O.BOX 272, Debre Tabor, Ethiopia. ${ }^{2}$ Department of Nursing, College of Medicine and Health Science, Bahir Dar University, Bahir Dar, Ethiopia.

Published online: 07 May 2020 